\title{
MOBILE LEARNING: APRENDENDIZAGEM COM MOBILIDADE
}

Luiz Fernando da Silva ${ }^{1}$, Eder Diego de Oliveira ${ }^{2}$, Marcelo Bolfe

${ }^{1}$ - Discente no Curso de Tecnologia em Análise e Desenvolvimento de Sistemas - Universidade Tecnológica Federal do Paraná. ${ }^{2}$ - Mestrando em Ciências da Computação - Universidade Estadual de Londrina. ${ }^{3}$ - Mestre em Educação pela Universidade do Oeste Paulista. E-mail: - professorluiz.sm@gmail.com

\section{RESUMO}

O presente artigo busca definir o conceito de Aprendizagem com Mobilidade, ou Mobile Learning (m-learning), as contribuições desse método ao processo de ensino aprendizagem, levando-se em conta a nova configuração das interações nesse processo, onde os atores se encontram separados fisicamente e, muitas vezes, geograficamente e atinar para com a possibilidade daquele ocorrer distante dos espaços físicos formais de educação. Para tal, foram realizadas pesquisas e estudos de artigos e obras científicas sobre o assunto, contendo as principais definições da tecnologia do m-learning, bem como os dispositivos móveis utilizados na mediação do processo ensino aprendizagem a distância e como tal assunto vem tomando conta das discussões e tornando-se uma alternativa interessante ao ensino, principalmente em épocas em que o tempo parece ser o componente da vida social que muitos indivíduos carecem, assim este tipo de tecnologia entra como uma ferramenta de auxílio na interação aluno e professor.

Palavras-chave: Aprendizagem com Mobilidade; M-Learning; Educação à distância; Educação móvel; Tecnologias móveis e sem fio.

\section{INTRODUÇÃO}

Os métodos de ensino-aprendizagem veem, atualmente, passando por uma grande revolução devido às necessidades de locomoção e tempo que muitos alunos enfrentam. Esse tipo de impasse não é enfrentado apenas por estudantes, mas também é vivenciado por profissionais que necessitam de capacitação periódica. Torna-se, então, necessário criar mecanismos que possibilitem aos discentes e a profissionais continuarem a aprender, mesmo estando fora da instituição de ensino.

Para solucionar tais problemas muitas instituições já adotam, há algum tempo, o EAD, conhecido também como e-learning. O ensino a distância utiliza recursos computacionais para realizar interação entre aluno e professor, assim é possível assistir aulas, ter acesso aos materiais e interagir com o corpo docente e colegas de classe usando um computador conectado à Internet, porém essa prática já está tornando-se insuficiente em muitos lugares.

Assim, para proporcionar um ensino à distância mais interativo e dinâmico, tem-se aderido à comunicação móvel via celular, o chamado Mobile Learning ${ }^{1}$ (m-learning), a aprendizagem com

\footnotetext{
${ }^{1}$ Utilização de dispositivos móveis e portáteis quando usada para facilitar o acesso à informação em programas de ensino.
} 
mobilidade. Basicamente, o m-learning faz uso das tecnologias de redes sem fio, dos novos recursos fornecidos pela telefonia celular, da linguagem XML, da linguagem Java, do protocolo WAP, serviços de mensagens curtas (SMS), da capacidade de transmissão de fotos, serviços de email, serviços de mensagem multimídia (MMS).

Segundo (MARÇAL, ANDRADE, RIOS, 2005, p. 03), os objetivos de uma aplicação m-learning são:

I. Melhorar os recursos para o aprendizado do aluno, que poderá contar com um dispositivo computacional para execução de tarefas, anotação de ideias, consulta de informações via Internet, registro de fatos através de câmera digital, gravação de sons e outras funcionalidades existentes;

II. Prover acesso aos conteúdos didáticos em qualquer lugar e a qualquer momento, de acordo com a conectividade do dispositivo;

III. Aumentar as possibilidades de acesso ao conteúdo, incrementando e incentivando a utilização dos serviços providos pela instituição, educacional ou empresarial;

IV. Expandir o corpo de professores e as estratégias de aprendizado disponíveis, através de novas tecnologias que dão suporte tanto à aprendizagem formal como à informal;

V. Fornecer meios para o desenvolvimento de métodos inovadores de ensino e de treinamento, utilizando os novos recursos de computação e de mobilidade.

No entanto, vale referenciar-se os aspectos dúbios desse processo e que já foram demonstrados por estudiosos do assunto, pois, em se tratando de tecnologias móveis, alguns aspectos negativos podem ser decorrentes, tais como o excesso de informações, sem que o receptor consiga processá-las para uma utilização eficiente; as interações adquirirem um nível bastante alto de complexidade, além do impacto na qualidade de vida das pessoas, já que esta tecnologia possibilita a quebra da fronteira entre a vida pessoal e a vida profissional, fazendo com que estas se interliguem cada vez mais, além da qualidade desse aprendizado, se o m-learning não fica restrito a um nível informacional (ZANELLA, SCHLEMMER, BARBOSA, REINHARD, 2007).

A educação sempre foi uma das principais preocupações e prioridades para uma sociedade que busca enriquecimento em todos os aspectos. Os métodos ultrapassados, pouco intuitivos, e a crescente necessidade de capacitação, formação e atualização profissional, aliada à exigência de mobilidade, contribuíram para o surgimento deste tipo de tecnologia. Até a rede mundial de 
computadores mudou sua forma e alguns portais adaptaram-se a telas pequenas de celulares, para que a informação pudesse chegar a qualquer pessoa e em qualquer lugar.

Este artigo, portanto, tem por objetivo apresentar um estudo sobre aprendizagem com mobilidade, no qual será desenvolvida uma aplicação para criar uma interação entre alunos e professores através de dispositivos móveis. Nele, são apresentadas reflexões sobre o assunto, e contribuições para projeto futuros.

\section{OBJETIVOS}

O m-learning não almeja substituir nenhum processo de ensino aprendizagem, pelo contrário, esta tecnologia possibilita ser um tópico auxiliador neste processo, sendo apenas um meio de interação e ajudando o discente em suas atividades. O objetivo dessa pesquisa é mostrar que os dispositivos móveis podem ser muito além de um instrumento de entretenimento e diversão, a intenção é procurar mostrar como um aplicativo móvel através de suas funcionalidades pode ser um objeto relevante quando falamos em educação.

\section{METODOLOGIA}

O estudo sobre a tecnologia do m-learning concentrou-se em referenciais bibliográficos, adotando pesquisa documental, utilizando publicações, especificamente, documentos localizados via ferramentas de busca na Internet. Outro fator importante para a pesquisa foi a prototipação da aplicação móvel, para realizar uma análise técnica das possiblidades e limitações da ferramenta.

O m-learning tem como meio de comunicação, a Internet. É através desta que os envolvidos poderão trocar informações e realizar interações. Por tal motivo, a WebML foi definida como metodologia aplicada no desenvolvimento da ferramenta. Esta estabelece graficamente especificações formais incorporadas em um processo completo de design o qual pode ser visto através de ferramentas, como WebRatio. A vantagem de usar esse tipo de metodologia é o fato de ser específica para a web e, também a possibilidade de poder retornar a qualquer fase em qualquer momento do desenvolvimento da aplicação, para possíveis correções e, conforme figura 1.

O Web Modeling Language é uma notação visual para especificar a composição e a navegação de aplicações de hipertexto. Construído com padrões populares como Entidade-Relacionamento e UML, o Web Modeling Lan- 
guage permite especificar complexas aplicações Web em plataformas diferentes. [CERI, FRATERNALI e BONGIO, 2000]

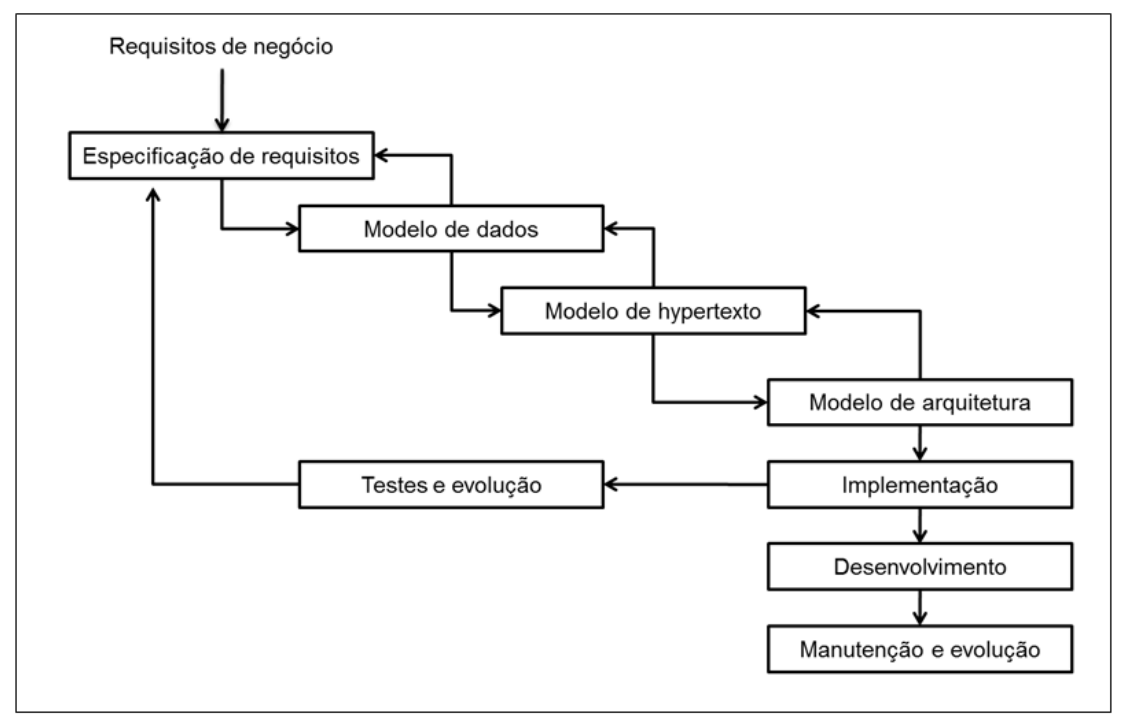

Figura 1. Estrutura do webML

Fonte (CERI, FRATERNALI e BONGIO, 2000)

A WebML procura descrever aplicações através de quatro dimensões (CERI, FRATERNALI e BONGIO, 2000):

- Modelo de estrutura: expressa o conteúdo dos dados do site em termos de entidades relevantes e relacionamentos. Equivalente a representações como diagrama entidade-relacionamentos e diagramas de classe.

- Modelo de Hipertexto: descreve um ou mais hipertextos que podem ser publicados no site. Cada hipertexto diferente define uma visão no site. A descrição da visão do site consiste de dois submodelos

a. Modelo de composição: especifica quais páginas compõem o hipertexto e quais unidades de conteúdo fazem parte da página.

b. Modelo de navegação: expressa como as páginas e o conteúdo dos dados está ligada no hipertexto.

- Modelo de apresentação: define o layout e aparência gráfica das páginas, independentemente do dispositivo de saída ou da linguagem de renderização. Pode ser específico de uma página ou genérica para um grupo de páginas.

- Modelo de personalização: representação das características específicas de um usuário ou grupo através de entidades predefinidas no diagrama de estruturas. 


\section{RESULTADOS}

Através dos estudos e pesquisas é afirmativo relatar que as tecnologias móveis estão entrando como grande recurso na área educacional, seu uso cresce de forma progressiva, retirando os questionamentos e desconfianças que existiam.

Os protótipos desenvolvidos através desse estudo têm como principal foco o aluno e, mostrar que o celular, smartphone ou tablet pode ser muito mais útil que apenas uma ferramenta de entretenimento. A aplicação possibilita ao aluno interagir no curso, como se estivesse em sala de aula. A preocupação foi mostrar como a ferramenta em um dispositivo móvel pode auxiliar os alunos na participação de aulas, sejam presenciais ou à distância, sejam alunos de escolas regulares ou instituições universitárias, ou mesmo profissionais de empresas.

\section{DISCUSSÃO}

A tecnologia é, inegavelmente, o aspecto principal desse século, forçando uma nova configuração do mundo, com o advento da denominada pós-modernidade, abrigando uma perceptível mudança nas relações de produção entre os homens, o que acaba por afetar a vida social como um todo. As interações se processam, então, num ritmo mais acelerado, em um mundo interligado em redes, onde a tecnologia computacional é a grande catapulta para o tão esperado progresso das nações.

No entanto, não se pode falar em progresso, em evolução em escala mundial dos negócios, das formas de produção, da vida social, sem mencionar os indivíduos que está formando-se para participar dessa alardeada (re)evolução, e que também serão, ao mesmo tempo, os artífices do momento histórico vivido. Para isso, a Educação é escalada como a propulsora em constituir esses indivíduos, cujas formas de conhecer, de pensar e se relacionar com o conhecimento não siga mais uma lógica determinista e mecanicista diante da realidade social, caracterizada por espaços territoriais sem fronteiras e comércios transnacionais.

Diante disso, o conhecimento não pode mais se dar de maneira linear, mas em sua forma descontínua, transdisciplinar, como a própria informática e seus avanços na área da comunicação e da informação. De fato, a Internet é a característica que a transdiciplinaridade traz em seu bojo, com seus espaços virtuais e simulados, onde indivíduos interagem com o conhecimento e com seus pares.

É notável, por isso mesmo, os avanços trazidos para a educação, em todas as suas formas, pelo desenvolvimento da tecnologia computacional, com seus dispositivos móveis e sem fio, por 
exemplo, modificando a relação entre os atores principais do processo de ensino aprendizagem, professores e alunos, e a interação com o conhecimento. A exemplo dos espaços territoriais do mundo pós-moderno, os espaços físicos onde acontecem a aprendizagem também perderam suas fronteiras.

Assim, telefones celulares, palmtops, laptops e smartphones, por exemplo, tornam-se importantes dispositivos mediadores do processo de ensino aprendizagem, abrindo possibilidades de novas propostas para a formação e qualificação de profissionais, cujo estado de mobilidade intensa também é um aspecto imposto pelo mundo na pós-modernidade.

Nesse contexto, a Aprendizagem com Mobilidade (mobile learning, ou m-learning), assunto discutido nesse trabalho, torna possível o acesso, em tempo real, pelos chamados espaços virtuais, ao conhecimento sistematizado, ampliando-se o ato educativo para além das salas de aulas, tornando o processo de ensino aprendizagem algo mais interativo, centrado no indivíduoaprendiz, de caráter colaborativo, já que praticamente se extingue, nos ambientes virtuais, as distâncias físicas e geográficas entre professores-alunos e alunos-alunos.

\section{CONCLUSÃO}

A Aprendizagem com Mobilidade cumpre um papel importante no próprio desenvolvimento dos métodos educativos, enquanto seu advento é pauta de discussões das várias ciências, como as da Educação, Psicologia e as Ciências da Computação, por exemplo, que encaram uma nova forma de relação entre indivíduos aprendizes e aprendizado.

Há algum tempo, a metodologia EAD (e-learning) pareceu ser um exemplo extraordinário de tecnologia aplicada à educação. No entanto, tornou-se obsoleta em não derrubar alguns paradigmas, como os dos espaços formais e fixos em que se processam o ensino aprendizagem. 0 método do m-learning, no entanto, inova, mostrando que a tecnologia móvel, que mediará o conhecimento e os indivíduos aprendizes, permite que as ações no ato educativo sejam negociadas, dinamizadas, para além de contextos pré-estabelecidos.

É de praxe que alternativas que se mostrem com caráter redentor das práticas em educação sejam questionadas e passem pela criticidade das teorias específicas. Assim também ocorre com a metodologia m-learning, pois foi apontado que as tecnologias de informação e comunicação móveis e sem fios (as TIMS), usadas no processo de ensino aprendizagem, causam uma verdadeira sobrecarga de informações, muitas vezes só recebidas, mas não processadas pelo 
indivíduo aprendiz, além do caráter meramente instrucional da referida metodologia e a quebra da demarcação do território profissional e do pessoal.

A tecnologia sempre esteve em parceria com o desenvolvimento humano, desde que o homem pôs o fogo a serviço de uma verdadeira melhoria na sua qualidade de vida, a milhares de anos passados. Atualmente, a tecnologia cumpre o mesmo papel: de alguma maneira, facilitar a interação do indivíduo com o mundo que o rodeia e também com os seus pares. Seja em processos de trabalho, ou mesmo para adquirir um conhecimento novo ou aprimorar o já estabelecido, não se pode relegar o avanço tecnológico, como pressuposto da própria história da humanidade no planeta.

\section{REFERENCIAS}

CERI, Sefano; FRATERNALI, Piero; BONGIO, Aldo. "Web Modeling Language (WebML): a Modeling Language for Designing Web Sites". WWW9 Conference, Ams-terdam, May 2000. Disponível em: http://webml.org/webml/upload/ent5/1/www9.pdf. Acesso em 31 março 2013.

MARÇAL, Edgar; ANDRADE, Rossana; RIOS, Riverson. Aprendizagem utilizando dispositivos móveis com sistemas de realidade virtual. Novas Tecnologias na Educação, Porto Alegre, V.3, N. 1, Maio 2005. Disponível em:

http://lumenagencia.com.br/dcr/arquivos/a51_realidadevirtual_revisado.pdf. Acesso em: 15 abril 2013.

ZANELLA, A. ; SCHLEMMER, Eliane; BARBOSA, Jorge Luis Victória ; REINHARD, Nicolau . MLearning ou Aprendizagem com Mobilidade: um estudo exploratório sobre sua utilização no Brasil. In: XXX Encontro Nacional dos Programas de Pós-Graduação em Administração, 2007, Rio de Janeiro. $\quad 2007 . \quad$ v. $1 . \quad$ p. 1-17. Disponível em: http://gpedunisinos.files.wordpress.com/2009/06/art_m-learning-ou-aprendizagem-commobilidade.pdf. Acesso em: 03 Abril 2013. 